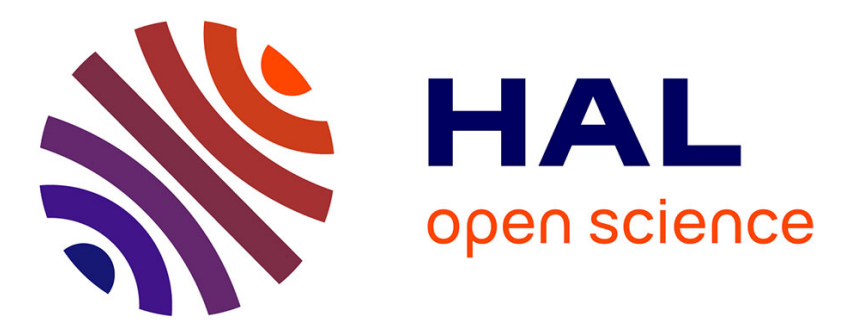

\title{
High peak power single-frequency MOPFA for lidar applications.
}

\author{
Laurent Lombard, Guillaume Canat, Anne Durécu, Agnès Dolfi-Bouteyre, \\ Matthieu Valla, Béatrice Augère, Didier Goular, Claudine Besson
}

\section{- To cite this version:}

Laurent Lombard, Guillaume Canat, Anne Durécu, Agnès Dolfi-Bouteyre, Matthieu Valla, et al.. High peak power single-frequency MOPFA for lidar applications.. CLRC 18th Coherent Laser Radar, Jun 2016, BOULDER, United States. hal-01354707

\section{HAL Id: hal-01354707 https://hal.science/hal-01354707}

Submitted on 19 Aug 2016

HAL is a multi-disciplinary open access archive for the deposit and dissemination of scientific research documents, whether they are published or not. The documents may come from teaching and research institutions in France or abroad, or from public or private research centers.
L'archive ouverte pluridisciplinaire HAL, est destinée au dépôt et à la diffusion de documents scientifiques de niveau recherche, publiés ou non, émanant des établissements d'enseignement et de recherche français ou étrangers, des laboratoires publics ou privés. 


COMMUNICATION A CONGRES
High peak power single-frequency
MOPFA for lidar applications
L. Lombard, G. Canat, A. Durécu, A. Dolfi-Bouteyre,
M. Valla, B. Augère, D. Goular, C. Besson
CLRC 18 th Coherent Laser Radar
BOULDER, U.S.A
27 juin-1 juillet 2016
TP $2016-447$

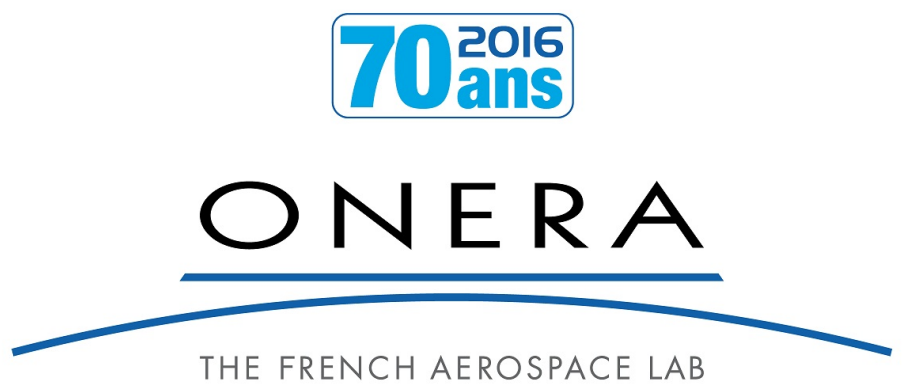




\title{
High peak power single-frequency MOPFA for lidar applications
}

\author{
Laurent Lombard, Guillaume Canat, Anne Durécu, Agnes Dolfi-Bouteyre, \\ Matthieu Valla, Beatrice Augère, Didier Goular, Claudine Besson \\ Onera, the French Aerospace Lab, Palaiseau, France \\ Laurent.Lombard@onera.fr
}

\begin{abstract}
Long range coherent detection wind lidars have many applications in the fields of wind farms and aircraft safety. Fiber laser sources emitting around $1.5 \mu \mathrm{m}$ show key advantages such as versatility, modularity and robustness of alignments to vibrations. However, nonlinear effects such as Stimulated-Brillouin-Scattering limit achievable peak power because of strong fiber core confinement. Wind lidars based on fiber laser technologies thus operate in a regime with low energy per pulse (typically $10 \mu \mathrm{J}-1 \mathrm{~mJ}$ ) and high pulse repetition frequency (typically $5-50 \mathrm{kHz}$ ). We investigated various technologies to improve peak power in $1.5 \mu \mathrm{m}$ fiber lasers such as special large mode area (LMA) fiber designs or strain management. Integration of a high peak power source in ONERA LICORNE wind lidar enabled to achieve air speed profiles up to record ranges of $16 \mathrm{~km}$ within $0.1 \mathrm{~s}$ averaging time.
\end{abstract}

Keywords: Coherent Laser Radar, Laser, Pulse Fiber Amplifier, Coherent Combining

\section{Introduction}

A typical coherent fiber LIDAR set up is depicted on Figure 1. The master oscillator is a continuous laser diode that goes through an acousto-optic modulator (AOM) which shapes the pulse. It is then amplified through a fiber preamplification stage and a filter (BPF) and a booster stage. At the output of the booster stage, the beam is polarized, quasi-single mode and its temporal shape is optimized for efficient coherent detection. Most systems emit around $1545 \mathrm{~nm}$ which corresponds to high gain in erbium doped fibers and a good atmospheric transmission. The assets of fiber lasers are their high efficiency enabling wall plug efficiency of $10 \%$ to $15 \%$, their size -the volume of a coherent $2 \mathrm{~W}$ fiber laser is the size of a thick bookand their reliability due to spliced connectors.

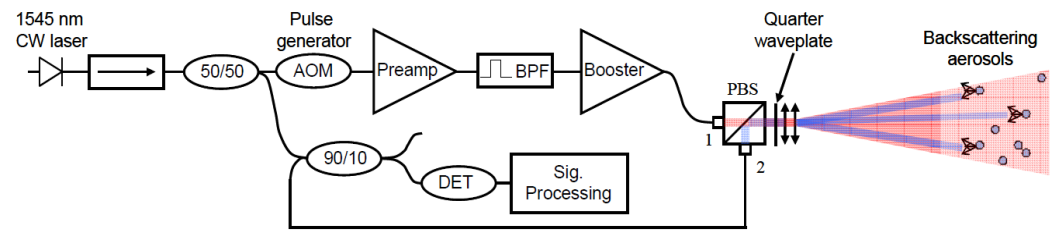

Figure 1: MOFPA coherent fiber LIDAR setup

\section{High spectral brillance all fibered sources and SBS mitigation}

ONERA has developed a specific know-how in high peak power, narrow linewidth pulsed fiber lasers and amplifiers. The additional laser power provides increased coherent LIDAR capability in range and scanning of large areas but also better system resistance to adverse weather conditions.

To reach long range within a short acquisition time, coherent wind LIDARs require high peak power $(\sim \mathrm{kW})$, narrow linewidth (few $\mathrm{MHz}$ ) pulsed laser sources with nearly Fourier transform limited pulse duration $(\sim 1 \mu \mathrm{s})$. Eyesafe, all-fiber laser sources based on MOPFA (master oscillator, power fiber amplifier) architecture offer many advantages over bulk sources such as low sensitivity to vibrations, efficiency and versatility. In the MOFPA coherent fiber LIDAR set up shown on Figure 1, the pulses are 
amplified in a sequence of fiber amplifier stages with increasing pump power and core size which are separated by isolators and band-pass filters. MOFPA designers seek for fibers with low numerical aperture (NA) which is favorable to single mode guiding and low amplified spontaneous emission (ASE) in order to get high system efficiency.

Narrow linewidth pulsed MOPFA are usually limited in peak power by nonlinear effects arising in the fiber such as Stimulated Brillouin Scattering (SBS) to a few 10s-100s Watts in standard fibers [1]. In single-mode fibers, the SBS threshold is reached when the peak power time length product reaches about $80 \mathrm{~W} . \mathrm{m}$. The high power density generates acoustic waves into the fiber core which acts as a grating. The light transmitted by the fiber saturates and part of this light is backscattered by the grating. In fiber amplifiers, the backscattered light may be amplified into the active fiber generating high peak power backscattered pulses potentially harmful for beforehand components [2].

The strength of the Brillouin nonlinearities in a fiber can be quantified by the intensity length product:

$$
B=g_{B} \frac{\int_{0}^{L} P(z) d z}{A_{e f f}}=\frac{g_{B} P(L) L_{e f f}}{A_{e f f}}
$$

where $g_{B}$ is the Brillouin gain, $\mathrm{L}$ is the fiber length, $A_{\text {eff }}$ is the effective area of the fundamental mode, $\mathrm{P}(\mathrm{z})$ is the signal power distribution along the fiber, $\mathrm{L}_{\text {eff }}$ is the effective length. For passive fiber the effective length is equal to the fiber length and for active fiber the effective length depends on the fiber gain along the fiber [3]. From (1) it appears that there are three ways to act on the nonlinearities.

\subsection{Increase of mode area}

The first way is to increase the fundamental mode effective area. Large-Mode-Area (LMA) fibers, with large core diameter and low numerical aperture (NA) may be used to increase the mode area but the fiber tends to guide higher order transverse modes degrading the beam quality. A good spatial quality is crucial for many applications. For instance in a coherent detection LIDAR when the beam quality factor $\mathrm{M}^{2}$ is increased from 1 to 1.7 we expect the Carrier-to-Noise Ratio (CNR) to decrease by $3 \mathrm{~dB}$ [4]. The most efficient doped fibers today are based on the Erbium-Ytterbium codoping of phosphosilicate glasses. This composition has two important limitations. First the core refractive index is quite large and special pedestal structures are needed to reduce the NA to 0.09 and limit the proportion of higher order transverse modes. A second limitation is that the core itself is usually inhomogeous with a central dip in the refractive index profile resulting in a poor beam spatial quality.

To go beyond this core diameter limit, IPHT and ONERA have built a $40 \mu \mathrm{m}$ core diameter multifilament-core fibers (MFC) to amplify high peak power pulses [5]. In this technology the fiber core is replaced by microstructured core composed of 37 Erbium-Ytterbium doped filaments surrounded by fluorine doped silica. It was shown that this structure behaves as an effectively singlemode fiber as the light only sees an average index value for the structured core. Pulses with $940 \mathrm{~W}$ peak power, $1 \mu \mathrm{s}$ duration and $1 \mathrm{MHz}$ laser linewidth were achieved. The beam quality was good with $\mathrm{M}^{2} \sim 1.3$. However this laser setup was not all-fiber. Indeed MFC fiber manufacture and integration in all-fiber lasers systems are challenging.

Another method to increase the core size while preserving a good beam quality is to change the core composition. We have tested phosphoaluminosilicate glass fibers (PAS). It has been previously demonstrated that the simultaneous codoping by alumina and phosphorous results in the reduction of the refractive index leading to lower NA cores [6], [7]. We have tested a double cladding PAS ErbiumYtterbium doped fiber with a $30 \mu \mathrm{m}$ diameter core with a pedestal and $300 \mu \mathrm{m}$ inner cladding. The core NA is 0.09 with respect to the pedestal. This fiber can be highly doped and we managed to make an efficient power amplifier with a short piece of fiber only $2 \mathrm{~m}$ long. When the pump power is increased, the pulse peak power is increasing steadily up to $770 \mathrm{~W}$ peak power corresponding to a $650 \mathrm{~ns}$ pulse 
energy of $450 \mu \mathrm{J}$ (Figure 2 left). The ASE fraction in the total output power is $6 \%$ at that point and the slope efficiency is $23 \%$. For $108 \mathrm{~ns}$ pulses, the peak power is increased up to the SBS threshold at $1120 \mathrm{~W}$ (Figure 2 right). The ASE fraction is then below 1\%.
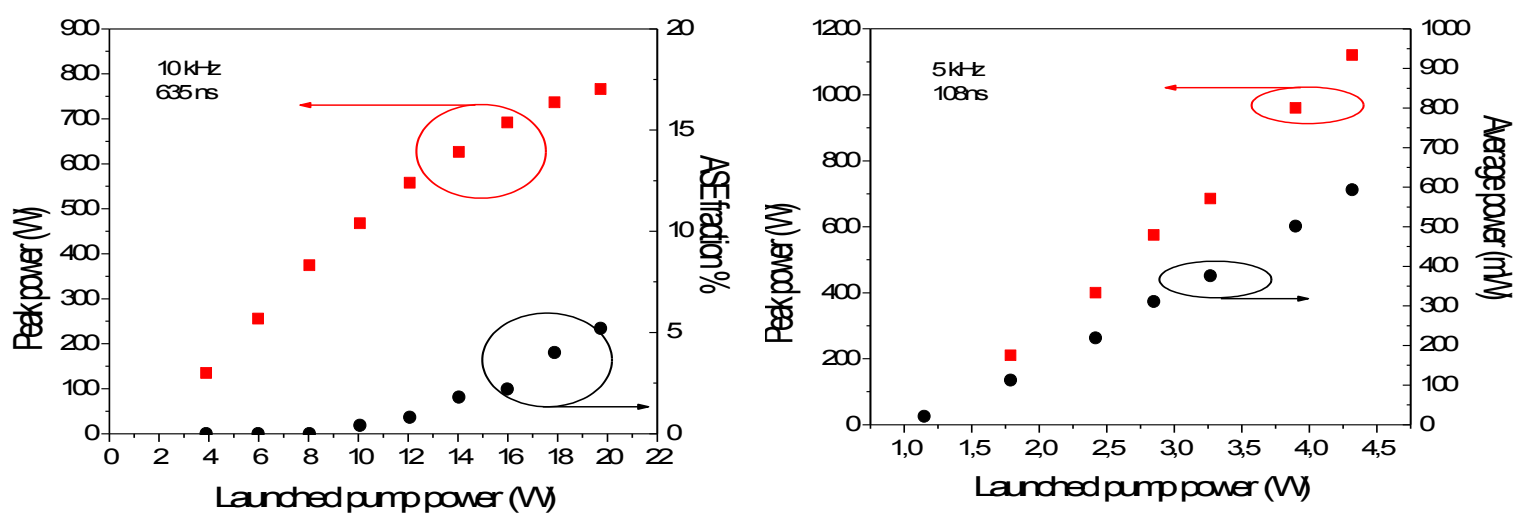

Figure 2. Pulse peak power with respect to launched pump power in the pulsed setup. Left: pulse duration $=635 \mathrm{~ns} ; \mathrm{PRF}=10$ $\mathrm{kHz}$. The ASE fraction in total power is shown on the right axis. Right: pulse duration $=108 \mathrm{~ns}$; PRF $=5 \mathrm{kHz}$. The average power is shown on the right axis.

\subsection{Strain distribution}

A second way to decrease the Brillouin effect is to minimize the integral of the power over the fiber length. By definition, this term is also equal to the product of fiber output power times effective length $\mathrm{L}_{\text {eff. }}$ In a standard fiber, all the fiber length contributes to Brillouin reflectivity at the same characteristic frequency. A strain gradient applied along the fiber can be used to make each fiber segment contribute to different frequencies and spread the reflected light spectrum [8] thus allowing higher optical peak power in the fiber before reaching the Brillouin threshold.

We have recently developed a high power single-frequency all-fiber MOPFA using high reliability passive components and this strain technique. This MOPFA was used in the first experimental demonstration of a fiber laser based wind LIDAR with more than $10 \mathrm{~km}$ range [9]. We have been able to spread the light reflected by $25 \mu \mathrm{m}$ core fiber resulting into an increase of more than $3 \mathrm{~dB}$ on the SBS threshold. Without the strain gradient, SBS limits the pulse peak power to $300 \mathrm{~W}(200 \mu \mathrm{J}$ per $600 \mathrm{~ns}$ pulses). The $\mathrm{M}^{2}$ is measured to be less than 1.3 in both axes. With the strain gradient applied to the doped fiber, peak power up to $630 \mathrm{~W}$ was achieved $(350 \mu \mathrm{J}$ per $550 \mathrm{~ns}$ pulses) (see Figure 3 ).

Since then, this technique has been applied to design HEPILAS a high power laser emitting at $1579 \mathrm{~nm}$ for space application (see Figure 4). The aim of this ESA project was to study a proof of concept for monitoring $\mathrm{CO}_{2}$ from space with a Differential Absorption LIDAR (DIAL) based on an all-fiber laser. 1.7 $\mathrm{kW}$ peak power was obtained for $150 \mathrm{~ns}$ pulses with excellent beam pointing stability. A factor of 3 gain was obtained with a modest value of strain so as to ensure that the fiber lifetime was compatible with a 5 years duration space mission. The laser was also designed so as to withstand $10 \mathrm{kRad}$ radiations thanks to iXfiber radhard active fiber [10]. 


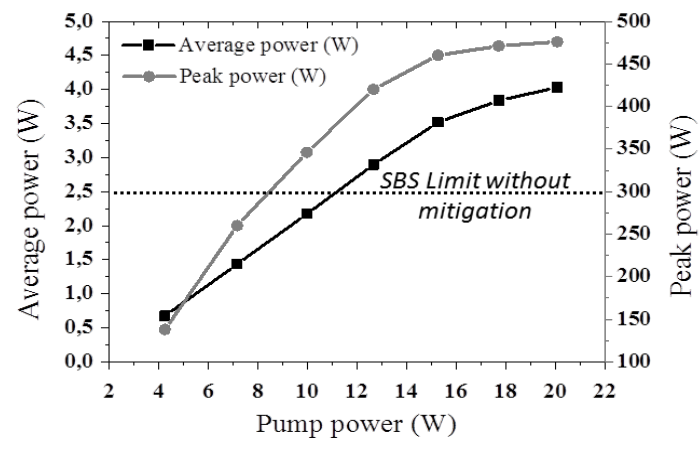

Figure 3. Evolution of the average power and peak power out of the high power amplifier with fiber straining. Dotted line: amplifier maximum peak power without strain implementation

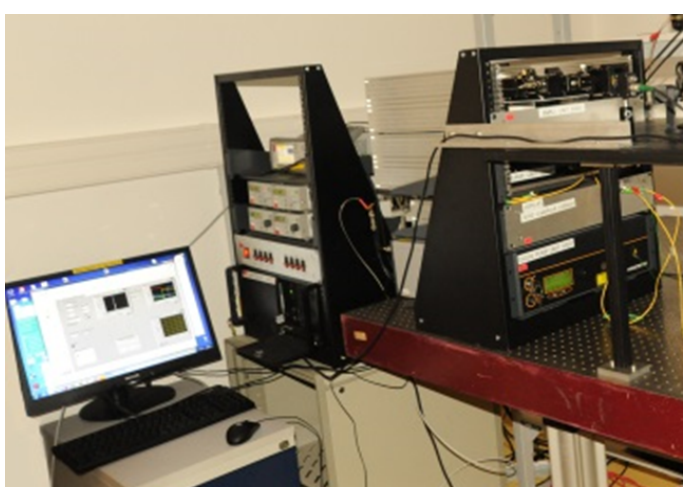

Figure 4 : the integrated engineering model of fiber laser HEPILAS for $\mathrm{CO} 2$ monitoring from space.

\subsection{Coherent combining}

The third strategy to tune equation (1) is to coherently add up the energy emitted by several fibers limited by SBS while preserving the good beam quality. Coherent Beam Combination (CBC) allows improving the output power of MOPFA sources by adding the outputs of single amplifiers. To achieve this, two or more amplifiers seeded by the same pulsed oscillator are coherently combined into a singlemode beam. To achieve high $\mathrm{CBC}$ efficiency the phase differences are compensated using a controller. We have recently demonstrated $\mathrm{CBC}$ of two amplifiers in $100 \mathrm{~ns}$-pulse regime limited to 95 and $123 \mathrm{~W}$, respectively resulting in peak power of $208 \mathrm{~W}$ [11]. Beam quality and spectral linewidth were maintained. This source has been successfully tested in a LIDAR configuration [12]. The setup of the CBC of two pulse amplifiers is shown on Figure 5.

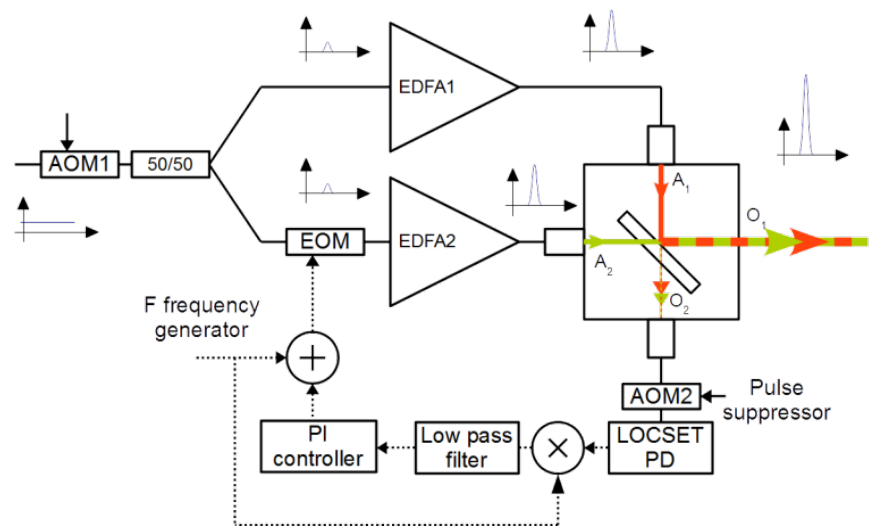

Figure 5. Coherently combined pulsed amplifier setup. Output O1 carries the total power of outputs A1 and A2.

In particular, we demonstrated that the pulse operation CBC phase controller does not impair the LIDAR performances. Indeed, the source of Figure 5 has been used as a Booster in a LIDAR Setup with 240ns pulse duration. We have compared the LIDAR performances when running (A) one amplifier at full power, (B) two amplifiers at half power and (C) two amplifiers at full power. The estimated wind speed time serie is shown on Figure 6. The Power spectral densities (PSD) of each recorded time evolutions are reported in Figure 7. 


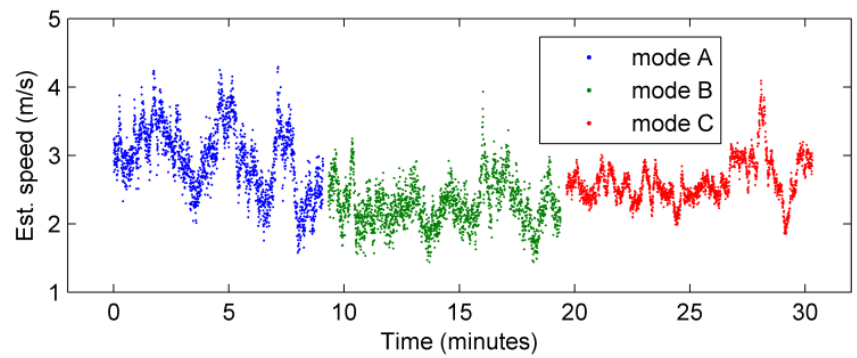

Figure 6 Estimated wind speed as recorded by the wind LIDAR in configurations A, B and C.
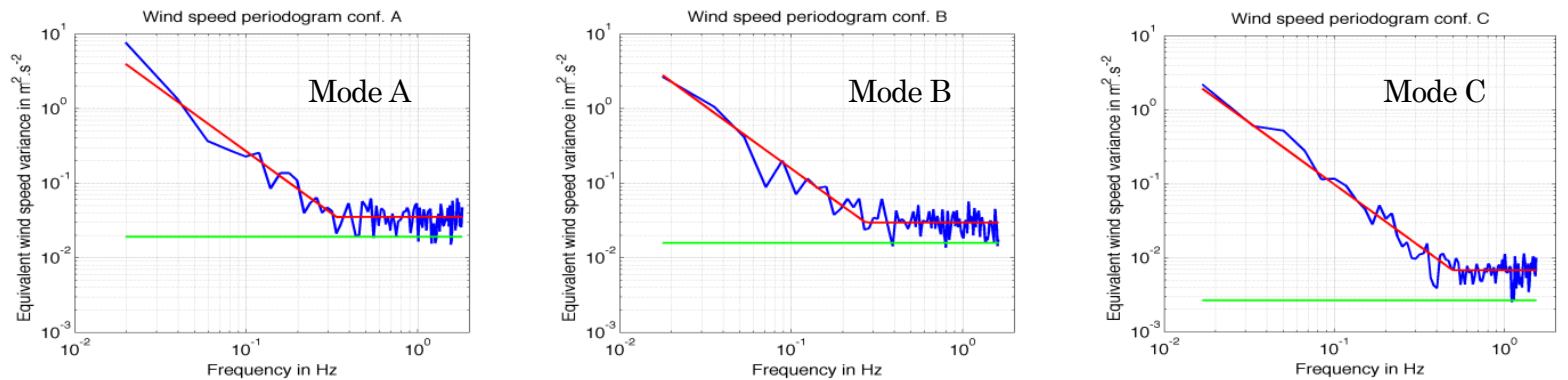

Figure 7 LIDAR performance comparison at 150m - Instrument noise floor comparison; blue: PSD of estimated wind speed from figure 6; red (low freq.): $\alpha f^{-5 / 3}$ Kolmogorov law ( $\alpha$ fitted to data); red (high freq.): LIDAR noise floor fitted to data; green:

LIDAR theoretical noise floor from estimated CNR (Cramer-Rao bound).

The extracted noise floors $(0.21 \mathrm{~m} / \mathrm{s}$ for mode A, $0.19 \mathrm{~m} / \mathrm{s}$ for mode B and $0.08 \mathrm{~m} / \mathrm{s}$ for mode C) show that no performance degradation has been measured when using CBC. When both amplifiers are run at full power, the expected LIDAR performance improvement is reached. In all cases, the LIDAR performance is very close to its optimum given by the Cramer-Rao bound.

Those results show the compatibility of coherent beam combining with coherent wind LIDAR. Potentially, tens to hundreds of those amplifiers can be combined by this technique.

\section{Long range Lidar measurements}

Building wind Lidars based on these high power sources enabled to achieve new record ranges in 2015 [13]. Onera wind lidar system LICORNE is based on the architecture shown in figure 1 and can implement various high power sources or new components. Sample results are illustrated on figure 8 in a fixed line of sight configuration: the wind-speed spectrogram shows that ranges beyond $15 \mathrm{~km}$ are achieved with $0.1 \mathrm{~s}$ averaging time. The carrier to noise ratio and the estimated wind-speed are averaged over 1024 pulses, corresponding to $0.1 \mathrm{~s}$ acquisition time with a simple centroïd frequency estimation method.

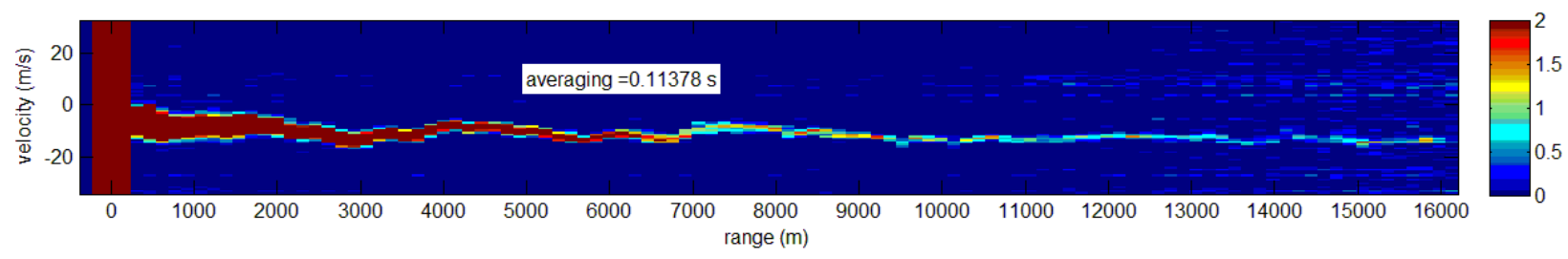

Figure 8: Wind-speed spectrograms versus range. Color scale is the power spectral density in $0.1 \mathrm{~s}$ average time.

\section{Conclusion}

To improve the peak power of the lidar sources and overcome nonlinear optics limitations, we have investigated various SBS mitigation techniques and integrated them in MOFPA architectures. For example, a high power all fiber laser demonstrator for $\mathrm{CO}_{2}$ monitoring from space has been developed. 
Using PAS Erbium-Ytterbium doped fiber with $30 \mu \mathrm{m}$ diameter, we achieved $1120 \mathrm{~W}$ peak power, $108 \mathrm{~ns}$ pulses. $630 \mathrm{~W}$ peak power, 550ns pulses were achieved using Onera strain gradient technique. Peak power can be further increased thanks to coherent beam combining of several fiber lasers and the principle of a wind lidar based on this technology has been demonstrated.

Onera wind lidars based on new high power, high spectral brightness, all-fiber sources have been used in various lidar configurations to demonstrate record ranges and EDR measurements. Indeed, horizontal air speed profiling up to $16 \mathrm{~km}$ in $0.1 \mathrm{~s}$ has been achieved, enabling to monitor large areas.

Optimized coherent lidar architectures with high power single mode fiber lasers offer new prospects for air speed and gas monitoring which should benefit to airport safety, aircraft navigation or atmosphere monitoring.

\section{References}

[1] G. Canat, Y. Jaouën, et J.-C. Mollier, « Performance and limitations of high brightness Er+3-Yb3+ fiber sources », Comptes Rendus Phys., vol. 7, n 2, p. 177-186, mars 2006.

[2] G. Kulcsar, Y. Jaouen, G. Canat, E. Olmedo, et G. Debarge, « Multiple-Stokes stimulated Brillouin scattering generation in pulsed high-power double-cladding Er/sup 3+/-Yb/sup 3+/-codoped fiber amplifier », IEEE Photonics Technol. Lett., vol. 15, nº 6, p. 801-803, juin 2003.

[3] Y. Jaouën, G. Canat, S. Grot, et S. Bordais, « Power limitation induced by nonlinear effects in pulsed highpower fiber amplifiers », Comptes Rendus Phys., vol. 7, nº 2, p. 163-169, mars 2006.

[4] J.-P. Cariou, B. Augere, et M. Valla, « Laser source requirements for coherent lidars based on fiber technology », Comptes Rendus Phys., vol. 7, nº 2, p. 213-223, mars 2006.

[5] G. Canat, S. Jetschke, S. Unger, L. Lombard, P. Bourdon, J. Kirchhof, J. V., A. Dolfi, et O. Vasseur, «Multifilament-core fibers for high energy pulse amplification at $1.5 \mu \mathrm{m}$ with excellent beam quality », Opt. Lett., vol. 33, nº 22, p. 2701-2703, nov. 2008.

[6] G. G. Vienne, W. S. Brocklesby, R. S. Brown, Z. J. Chen, J. D. Minelly, J. E. Roman, et D. N. Payne, « Role of Aluminum in Ytterbium-Erbium Codoped Phosphoaluminosilicate Optical Fibers », Opt. Fiber Technol., vol. 2, nº 4, p. 387-393, oct. 1996.

[7] A. N. Abramov, M. M. Bubnov, N. N. Vechkanov, A. N. Guryanov, K. V. Zotov, D. S. Lipatov, M. E. Likhachev, et M. V. Yashkov, «Fabrication of heavily Er2O3 doped aluminophosphosilicate glass fibers », Inorg. Mater., vol. 46, $\mathrm{n}^{\circ}$ 4, p. 439-444, avr. 2010.

[8] J. M. C. Boggio, J. D. Marconi, et H. L. Fragnito, « Experimental and numerical investigation of the SBSthreshold increase in an optical fiber by applying strain distributions », J. Light. Technol., vol. 23, $\mathrm{n}^{\mathrm{o}}$ 11, p. 3808-3814, nov. 2005.

[9] W. Renard, D. Goular, M. Valla, C. Planchat, B. Augere, A. Dolfi-Bouteyre, C. Besson, et G. Canat, « Beyond $10 \mathrm{Km}$ Range wind-speed measurement with a 1.5 \&amp;micro;m all-fiber laser source », 2014, p. AW1P.5.

[10] G. Canat, W. Renard, T. Robin, B. Cadier, J. L. Gouët, L. Lombard, A. Durecu, et P. Bourdon, « High peak power single frequency amplifiers based on efficient Erbium-Ytterbium doped LMA fibers », in 2015 European Conference on Lasers and Electro-Optics - European Quantum Electronics Conference, 2015, p. CJ_12_5.

[11] L. Lombard, A. Azarian, K. Cadoret, P. Bourdon, D. Goular, G. Canat, V. Jolivet, Y. Jaouen, et O. Vasseur, "Coherent beam combination of narrow-linewidth $1.5 \mu \mathrm{m}$ fiber amplifiers in a long-pulse regime », Opt. Lett., vol. 36, $\mathrm{n}^{\circ}$ 4, p. 523-525, février 2011.

[12] L. Lombard, M. Valla, C. Planchat, D. Goular, B. Augère, P. Bourdon, et G. Canat, « Eyesafe coherent detection wind lidar based on a beam-combined pulsed laser source », Opt. Lett., vol. 40, n 6, p. 1030-1033, mars 2015.

[13] C. Besson, B. Augere, G. Canat, A. Dolfi-Bouteyre, D. Fleury, D. Goular, J. Le Gouët, L. Lombard, C. Planchat, M. Valla, et W. Renard, « Recent achievements in Doppler Lidars for aircraft certification », présenté à ETTC, 2015. 